Egyptian

Orthodontic Journal

\title{
EFFECT OF HYPERBARIC OXYGEN ON MOBILITY OF ORTHODONTICALLY TREATED TEETH
}

\author{
Hany Salah El- Din Eid, BDS, MSD, DDSc., ${ }^{1}$ \\ Waleed El Sayed, BDS, MSD, PhD, ${ }^{2}$
}

\section{ABSTRACT:}

Objectives: The present study was designed to investigate the effect of hyperbaric oxygen therapy (H(BOT) on improving tooth mobility during orthodontic treatment using a Periotest. Methods: Twenty orthodontic cases ( $n=20)$ without severe skeletal discrepancies were used as subjects. For each subject, the mobility of the central and lateral incisors on both arches (U1, V2, L1, and L2) was measured immediately before orthodontic treatment (T1), after 12 months of treatment (T2), and after 3 months from $\mathcal{T} 2$ stage (T3) by use of a Periotest. The sample was randomly divided into two groups $(n=10)$. The first group was administered $\mathcal{H B O}$ for 60 minutes, at 2.5 ATA (atmospheres absolute) for five consecutive days immediately after T2 stage, and the second group served as a control. For both groups the mean values of $\mathcal{T} 1$ stages were calculated and compared to those of $\mathcal{T} 2$ and $\mathcal{T} 3$ stages in the same group. Results: At $\mathcal{T} 2$ and $\tau_{3}$ stages, the periotest mean values have increased for all the teeth in the second group without $\mathcal{H B O T}$ in comparison with those at T1 stage in the same group. However, in the first group that has been given $\mathcal{H} B O T$, the mean values have significantly increased at T2 stage compared with those at $\mathcal{T}_{1}$ stage, 6ut the mean values at T3 stage have significantly decreased compared with those at $\mathcal{T} 2$ stage in the same group. Conclusions: It is suggested that hyperbaric

1- lecturer of Orthodontics, Faculty of Dentistry, Misr University for Science and Technology, $6^{\text {th }}$ of October city, Egypt.

2- lecturer of Orthodontics, Faculty of Dentistry, Suez Canal University, Ismailia, Egypt. 
Egyptian

Orthodontic Journal

oxygen therapy (ḦBOT) may be useful in reducing tooth mobility noticed during and after orthodontic treatment.

\section{INTRODUCTION}

Recent advances in orthodontic techniques as well as increased demands on such specialty, was due to increased adult patient's awareness of functional and esthetic consequences of malocclusion. Massive histological changes occur in the periodontal tissue during the cascade of events that lead to orthodontic tooth movement. Such changes have been shown through previous extensive studies of experimental tooth movement. ${ }^{1-3}$ If the orthodontic forces were kept within the optimum levels, bone resorption occurs on the compressive side and bone apposition also occurs on the tension side, followed by a widening of the periodontal ligament (PDL) space, which is considered of great importance in the physiological extent of tooth movement migrating toward the compressive side due osteoclasts attack of the bone surface. ${ }^{3}$ In orthodontic tooth movement, the remodeling process in the PDL is repeated, ${ }^{4,5}$ and tooth mobility is affected substantially by remodeling as well as by anatomical alterations in the PDL space and alveolar bone height. ${ }^{6}$ Physiological tooth mobility is a product of the elastic attachment of the PDL between root and alveolar bone. ${ }^{7}$ At some point during active extensive tooth movement, the PDL is considerably widened, resulting in increased tooth mobility. It is generally recognized that tooth mobility increases during orthodontic treatment and is gradually restored to standard levels after completion of orthodontic treatment. It has been found that treatment with fixed orthodontic appliances may result in loss of marginal attachments. ${ }^{8-10} \mathrm{~A}$ reduced attachment alone or in combination with a possible short root might lead to tooth mobility, which in animal experiments has been shown to increase the risk of further breakdown of alveolar bone. ${ }^{11,12}$ Other animal studies have shown that increased tooth mobility in combination with plaque-induced gingivitis heightens the risk of tooth loss. ${ }^{13}$ Therefore tooth mobility has been used as an important indicator in the assessment of biomechanical characteristics of the periodontium and the availability of periodontal support throughout orthodontic treatment. ${ }^{6}$ 
Egyptian

Orthodontic Journal

Hyperbaric oxygen therapy (HBOT), even though has been used long time ago, its use is accelerating as a treatment option in both human and veterinary medicine as more chambers become available and knowledge of its benefits increase. It has several applications in emergency conditions such as carbon monoxide poisoning, treatment of venomous spider and snake bites, compartment syndrome, and central nervous system injury, as well as in more chronic disease states such as delayed wound healing. ${ }^{14}$ Hyperbaric therapy refers to placing the patient in a chamber to breathe oxygen produced at greater than one atmosphere. When oxygen is breathed at a pressure of 2 ATA (atmospheres absolute), it causes vasoconstriction by decreasing the blood flow rate by up to $20 \%$. The normal tissue pO2 is 30 to $40 \mathrm{mmHg}$, but in ischemia caused by infection, trauma or edema, oxygen levels fall much lower. ${ }^{15}$ Below $30 \mathrm{mmHg}$, fibroblast and leukocyte functions are severely compromised. Hypoxia $(15 \mathrm{mmHg})$ stimulates angiogenesis and capillary budding (if the periphery of the hypoxic area has adequate perfusion/oxygenation). Hyperbaric oxygen increases collagen formation for capillary growth through providing the required matrix to support this process. ${ }^{16} \mathrm{HBO}$ also promotes fibroblast replication, collagen formation and increased bactericidal function of leukocytes to take place while the patient is in the hyperbaric chamber. ${ }^{17}$ It has been found that compensation occurs by increasing the tissue oxygen tension ( $\mathrm{pO} 2$ ), which may reach 250 to $300 \mathrm{mmHg}$ when hyperbaric oxygen is applied. ${ }^{16} \mathrm{HBO}$ is routinely administered at 1 to 3 ATA. While the duration of an HBO session is typically 90 to 120 minutes, the duration, frequency, and number of sessions have not been standardized. ${ }^{18-20}$ Among the common surgical conditions where HBOT is used; gas gangrene, crush injuries, compartment syndromes and acute traumatic ischemias, enhancement of healing in selected problem wounds, exceptional blood loss anemia, necrotizing soft-tissue infections, refractory osteomyelitis, soft-tissue radionecrosis and osteoradionecrosis, compromised skin grafts and flaps, thermal burns, and intracranial abscesses. ${ }^{21,22}$ Hyper-oxygenation, vasoconstriction, bactericidal/bacteriostatic effect, angiogenesis and neovascularization, and direct pressure were found to be the effective mechanisms that enhance the healing of treatment conditions. ${ }^{18,19,21}$ Oxygen tension has a triggering role in bone remodeling. ${ }^{23}$ The increase 
Egyptian

Orthodontic Journal

in oxygen tension causes cellular differentiation to osseous tissue, whereas decreased oxygen tension results in cartilage formation. ${ }^{24}$ There is a direct relation between the increase in oxygen tension and increase in osteoblastic and osteoclastic activity, ${ }^{20}$ where HBO treatment was found to cause a significant increase in bone formation such that lamellar bone develops in the chamber canal. ${ }^{25}$ The beneficial effects of (HBOT) as an adjunct in the management of periodontitis have been reported. ${ }^{26-31}$ Based on the fact that oxygen tension is lower in deeper periodontal pockets, and this might favor a faster colonization of residual pockets by periodontopathosis. ${ }^{32-34}$ Thus, if such colonization has been arrested or reduced through (HBOT), it might lead to demolishing the cascade of events that might lead to initiation or further loss of alveolar bone height resulting to the eventual tooth mobility with varying degrees according to the extent of the existing causative factors. Monitoring and controlling tooth mobility during orthodontic treatment as well as near its conclusion, not only contributes to detection and reduction of risk factors, but also aids in the consolidation of stability during retention. The present study was designed to investigate the effect of hyperbaric oxygen therapy (HBOT) on improving tooth mobility induced or aggravated by orthodontic treatment using a Periotest.

\section{MATERIALS AND METHODS}

Twenty orthodontic cases age ranging from 19 to 24 years $(n=20)$ without severe skeletal discrepancies were used as subjects (12 males and 8 females). All patients appeared to be in good general health, had no obvious medical condition, or chronic debilitating disease which could affect the periodontal support of the tooth. Smoking, pregnancy and lactation cases were excluded from the sample. Subjects had no history of trauma, drug intake on regular basis or previous orthodontic treatment. Any form of initial gingivitis or periodontitis detected upon diagnosis due to local factors was arrested and controlled through scaling, root planning as well as meticulous oral hygiene measures prior to commencing recording of initial tooth mobility by at least 1 month. As a result of diagnosis, all patients were treated as nonextraction cases, using the same type of fixed orthodontic appliance and same treatment strategy. For each subject, the mobility of the central and lateral incisors on both arches 
Egyptian

Orthodontic Journal

(U1, U2, L1, and L2) was measured by use of a Periotest (Medizintechnik Gulden, Germany) (Fig 1). First recording was taken immediately before orthodontic treatment (T1). Second recording, taken after 12 months of treatment (T2), during which, leveling and alignment of teeth was completed and a continuous 18 mil steel orthodontic arch wire was inserted and cinched back. Third recording was taken after 3 months from second recording (T3), during which, no orthodontic movements were attempted. The Periotest is an electronic device that measures the damping characteristics of the periodontium. The apparatus consists of a microcomputerized measuring and steering device that connects to a handpiece with a tapping head (a built-in metal rod). The Periotest is designed to precisely calculate the tooth mobility from the state of the rebound of the tapping head. The tapping head in the handpiece beats the surface of the tooth at a rate of four times per second. The duration of the contact of the tapping head on the tooth surface is measured by the instrument that calculates the Periotest value to indicate tooth mobility ${ }^{35}$. At each stage, the measurements were taken three times for each tooth with the brackets in place with no wires attached, and then the average values were used in the calculations. The device was used according to the manufacturer's instructions. The patient's head was placed against the headrest with the tooth perpendicular to the floor. The handpiece was held to the buccal surface of the tooth at the center of the anatomic crown with a distance of less than $4 \mathrm{~mm}$ from the labial surface of the incisor. The sample was randomly divided into two groups $(n=10)$. The first group was administered $\mathrm{HBO}$ for 60 minutes, at 2.5 ATA (atmospheres absolute) for five consecutive days starting immediately the next day after T2 stage at the Egyptian Air Force Aero- Medical Institute ,Cairo, Egypt (Fig 2). The second group had no HBOT and served as a control. For evaluation of the measured tooth mobility, the means and standard deviations of the Periotest values were calculated for each tooth of each stage. Statistics was done using Epi-Info software. Mean and standard deviation was used for summarizing data. Student's $t$ test was used for testing significant results between two sample means; paired t test was used for testing significant results between mean values for the same individuals before and after intervention. Significant results is considered if $p<0.05$, high significant results was considered if $p<0.01$. 
Egyptian

Orthodontic Journal

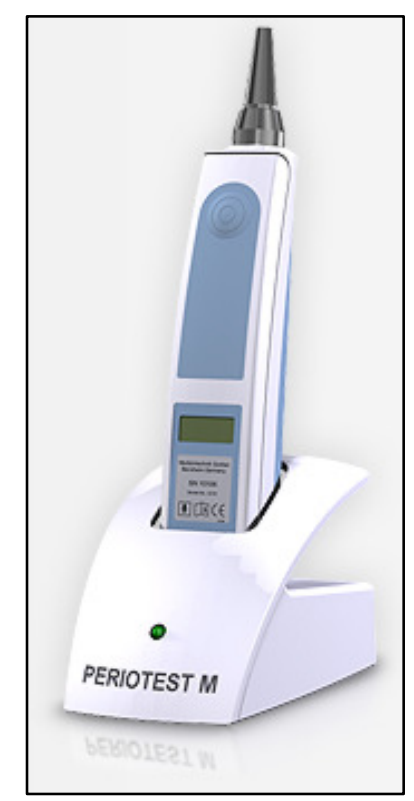

Fig 1: Periotest (Medizintechnik Gulden, Germany)

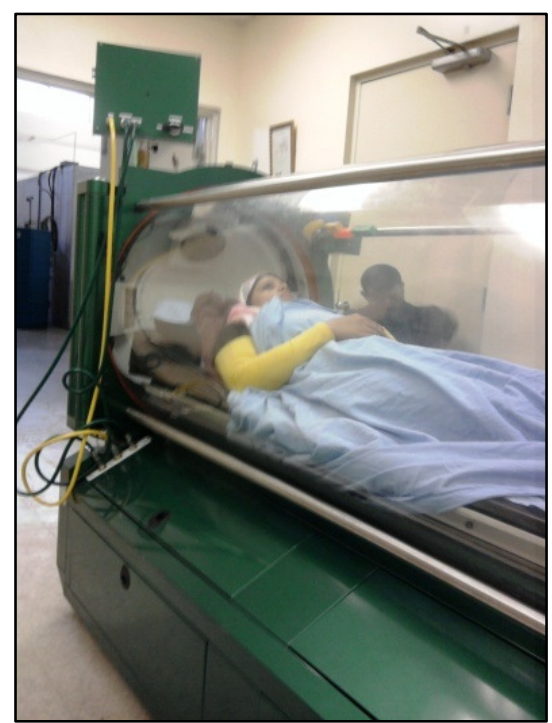

Fig 2: Hyperbaric chamber used in the study at the Egyptian Air Force Aero- medical institute. 
Egyptian

Orthodontic Journal

\section{RESULTS}

There was no statistical difference between studied groups regarding all measured teeth before orthodontic treatment at $\mathrm{T} 1(\mathrm{p}>0.5)($ table 1$)$.

Table (1): Differences between the studied groups in base line readings:

\begin{tabular}{|c|c|c|c|c|}
\hline Variables & Non HBOT group & HBOT group & $\boldsymbol{t}$ & $\boldsymbol{p}$ \\
\hline UR1 & $11.77 \pm 1.69$ & $11.71 \pm 1.73$ & 0.07 & 0.9384 \\
\hline UR2 & $11.48 \pm 1.8$ & $11.53 \pm 1.87$ & 0.06 & 0.9521 \\
\hline UL1 & $11.94 \pm 2.12$ & $11.89 \pm 1.93$ & 0.05 & 0.9565 \\
\hline UL2 & $11.53 \pm 1.79$ & $11.49 \pm 1.86$ & 0.04 & 0.9614 \\
\hline LR1 & $9.86 \pm 0.69$ & $9.85 \pm 0.62$ & 0.03 & 0.9732 \\
\hline LR2 & $8.4 \pm 1.05$ & $8.23 \pm 1.09$ & 0.36 & 0.7263 \\
\hline LL1 & $9.92 \pm 0.67$ & $9.82 \pm 0.76$ & 0.31 & 0.7582 \\
\hline LL2 & $8.03 \pm 1.04$ & $8.01 \pm 0.98$ & 0.04 & 0.9651 \\
\hline
\end{tabular}

When comparing between T1 and T2 Periotest measurements; high significant increase was found in the mean values of all tested teeth in both groups $(\mathrm{p}<0.001)$. When comparing both groups at T2 measurements; slight increase was found in the mean values in non HBOT group than HBOT group ( $\mathrm{p}=\mathrm{UR} 1: 0.3753$, UR2: 0.3342 , UL1: 0.5866, UL2: 0.4899, LR1: 0.6781, LR2: 0.6385, LL1: 0.3904, LL2: 0.2658). When comparing both groups at T3 measurements; highly significant decrease was found in the mean values in HBOT group than non HBOT group ( $\mathrm{p}=\mathrm{UR} 1: 0.0018$, UR2: $0.0007, \mathrm{UL} 1: 0.0025$, UL2: 0.0009, LR1: 0.0003, LR2: 0.000, LL1: 0.000, LL2: 0.000). Comparison between the mean values of T2 and T3 measurements revealed highly significant decrease in the group subjected to HBOT $(p<0.001)$. Comparison between the mean values of T1 and T3 measurements revealed highly significant increase in the group not subjected to HBOT $(\mathrm{p}<0.001)$ (table 2). 
Egyptian

Orthodontic Journal

Table (2): Mean difference in readings on follow up for HBOT and non HBOT groups:

\begin{tabular}{|c|c|c|c|c|}
\hline \multicolumn{2}{|r|}{ UR1 } & non HBOT group & HBOT group & $\mathbf{p}$ \\
\hline $\mathrm{T} 1$ & Mean \pm SD & $11.77 \pm 1.69$ & $11.71 \pm 1.73$ & 0.9384 \\
\hline $\mathrm{T} 2$ & Mean $\pm \mathrm{SD}$ & $13.99 \pm 2.07$ & $13.13 \pm 2.16$ & 0.3753 \\
\hline $\mathrm{T} 3$ & Mean \pm SD & $13.53 \pm 2.18$ & $10.49 \pm 1.49$ & 0.0018 \\
\hline \multicolumn{5}{|c|}{ UR2 } \\
\hline $\mathrm{T} 1$ & Mean \pm SD & $11.48 \pm 1.8$ & $11.53 \pm 1.87$ & 0.9521 \\
\hline $\mathrm{T} 2$ & Mean $\pm \mathrm{SD}$ & $13.57 \pm 1.72$ & $12.66 \pm 2.34$ & 0.3342 \\
\hline $\mathrm{T} 3$ & Mean \pm SD & $13.3 \pm 1.66$ & $10.65 \pm 1.22$ & 0.0007 \\
\hline \multicolumn{5}{|c|}{ UL1 } \\
\hline $\mathrm{T} 1$ & Mean \pm SD & $11.49 \pm 2.12$ & $11.89 \pm 1.93$ & 0.9565 \\
\hline $\mathrm{T} 2$ & Mean $\pm \mathrm{SD}$ & $14.08 \pm 2.16$ & $13.56 \pm 2.04$ & 0.5866 \\
\hline T3 & Mean \pm SD & $13.81 \pm 2.11$ & $10.85 \pm 1.65$ & 0.0025 \\
\hline \multicolumn{5}{|c|}{ UL2 } \\
\hline $\mathrm{T} 1$ & Mean \pm SD & $11.53 \pm 1.79$ & $11.49 \pm 1.86$ & 0.9614 \\
\hline $\mathrm{T} 2$ & Mean $\pm \mathrm{SD}$ & $13.4 \pm 2.07$ & $12.71 \pm 2.29$ & 0.4899 \\
\hline $\mathrm{T} 3$ & Mean \pm SD & $13.18 \pm 1.91$ & $10.32 \pm 1.24$ & 0.0009 \\
\hline \multicolumn{5}{|c|}{ LR1 } \\
\hline $\mathrm{T} 1$ & Mean \pm SD & $9.86 \pm 0.69$ & $9.85 \pm 0.62$ & 0.9732 \\
\hline $\mathrm{T} 2$ & Mean \pm SD & $12.81 \pm 1.28$ & $12.59 \pm 1.04$ & 0.6781 \\
\hline $\mathrm{T} 3$ & Mean \pm SD & $12.6 \pm 1.22$ & $10.27 \pm 0.96$ & 0.0003 \\
\hline \multicolumn{5}{|c|}{ LR2 } \\
\hline $\mathrm{T} 1$ & Mean $\pm \mathrm{SD}$ & $8.4 \pm 1.05$ & $8.23 \pm 1.09$ & 0.7263 \\
\hline $\mathrm{T} 2$ & Mean \pm SD & $11.4 \pm 1.16$ & $11.15 \pm 1.18$ & 0.6385 \\
\hline $\mathrm{T} 3$ & Mean \pm SD & $11.16 \pm 1.10$ & $8.57 \pm 1.03$ & 0.000 \\
\hline \multicolumn{5}{|c|}{ LL1 } \\
\hline $\mathrm{T} 1$ & Mean \pm SD & $9.92 \pm 0.67$ & $9.82 \pm 0.76$ & 0.7582 \\
\hline $\mathrm{T} 2$ & Mean \pm SD & $12.63 \pm 1.01$ & $12.27 \pm 0.80$ & 0.3904 \\
\hline $\mathrm{T} 3$ & Mean \pm SD & $12.44 \pm 0.92$ & $10.1 \pm 0.91$ & 0.000 \\
\hline \multicolumn{5}{|c|}{ LL2 } \\
\hline $\mathrm{T} 1$ & Mean \pm SD & $8.03 \pm 1.04$ & $8.01 \pm 0.98$ & 0.9651 \\
\hline $\mathrm{T} 2$ & Mean \pm SD & $11.26 \pm 1.02$ & $10.79 \pm 0.80$ & 0.2658 \\
\hline $\mathrm{T} 3$ & Mean \pm SD & $10.88 \pm 0.96$ & $8.22 \pm 1.08$ & 0.000 \\
\hline
\end{tabular}


Egyptian

Orthodontic Journal

\section{DISCUSSION}

Among other methods and devices used in the literature to measure tooth mobility are dial meters and strain gages as well as techniques with laser holography and noncontact displacement sensors were developed. ${ }^{6}$ Even though they offer accurate values for tooth mobility by which the biomechanical properties of PDL can be calculated, the systems involve a huge apparatus, and it is not easy for clinicians to apply them to many teeth of many patients. In contrast, Periotest offers a simple and accurate method for clinically determining tooth mobility as it depends on the evaluation of viscoelastic behavior of the periodontium. ${ }^{35,36}$ In this study, the mean values at T1 stage were 11.8 for the upper central incisor, 11.5 for the upper lateral incisor, 9.8 for the lower central incisor, and 8.2 for the lower lateral incisor, which were larger than the mean values in the healthy permanent incisors (table 1). ${ }^{37}$ Possibly due to abnormal occlusal contact associated with tooth crowding may gradually induce the loss of supporting tissues for teeth. Knowing that, mobility is present in all teeth even if they appear to be healthy with normal alveolar bone support and tight PDL, that is due to the elastic attachment of the PDL between root and alveolar bone. ${ }^{7}$ It is generally known that tooth mobility occurs during orthodontic treatment due to widening and disorganization of PDL also due to root resorption that occurs sometimes during treatment. It is also worth to mention that the incidence of alveolar bone and root resorption becomes higher when the treatment duration becomes longer. ${ }^{38,39}$ In this study, although severe bone loss and apical root resorption secondary to orthodontic treatment could not be detected. However, one or two patient in every group started treatment with severe loss in alveolar bone height, also slight or mild root resorption was found in a few patients throughout the treatment, having in mind that all local factors were controlled prior to any Periotest recording. In our study, the 
mean change from $\mathrm{T} 1$ to $\mathrm{T} 2$ was highly significant increase in both groups, however no significant difference regarding $\mathrm{T} 1$ readings when the two groups were compared. That indicates that the patients selected for both groups were close and similar to a great extent regarding initial readings (table 1). At T2 comparison, the non HBOT group showed an increase in readings more than the HBOT by a thin margin, indicating that the treatment strategies applied for both groups was similar to a great extent. It is also worth to be noted that this mean increase between first and second Periotest measurements matched with the results obtained by Tanaka et $\mathrm{al}^{35}$ who measured teeth mobility also by means of a Periotest throughout the entire orthodontic treatment (table 2). Upon comparing the two groups regarding third readings (T3), highly significant difference between the two groups in the mean values of Periotest can be noticed from the P value (table 2), where UR1, UR2, UL1, UL2, LR1, LR2, LL1 and L L2 mean values in HBOT group changed from 13.13, 12.66, $13.56,12.71,12.59,11.15,12.27$ and 10.79 at $\mathrm{T} 2$ respectively to 10.49 , $10.65,10.85,10.32,10.27,8.57,10.1$ and 8.22 respectively at T3. These dramatic changes brought back the Periotest readings for that group almost close to T1 initial readings, mean while the non HBOT group showed a slight increase in T3 readings compared to T2 (Figs 3 and 4). It is not surprising to expect such effect of HBOT on tooth mobility, based on previous researches that supported the beneficial effects of HBOT as an adjunct in the management of periodontitis which is considered a prime factor that would eventually lead to tooth mobility. ${ }^{26-31}$ Also Filho et $\mathrm{al}^{15}$ designed a study to investigate the short-term effect of hyperbaric oxygen therapy as adjunctive to scaling and root planing in patients suffering from extremely severe generalized chronic periodontitis. In their study, which was the bases of selecting the time interval between $\mathrm{T} 2$ and $\mathrm{T} 3$ in our study, improved clinical parameters in 3 months was found after HBOT, regarding probing depth and attachment 
level. Thus, it is expected that HBOT could have beneficial effects on the initial periodontal treatment outcome, especially in patients who started out their orthodontic treatment with marked bone loss due to previous history of uncontrolled periodontitis (Figs 5 and 6). The effect of HBO is still under investigation. Although various researches have been conducted by several investigators, the duration, frequency, and cumulative number of sessions for HBO have not been standardized. In rabbits, $20 \mathrm{HBO}$ sessions for 60 minutes at 2.4 ATA, $100 \%$ inspired oxygen flow twice a day were performed before free bone grafting, and 10 sessions were performed after the bone grafting. ${ }^{40}$ In a similar study, HBO treatment was performed for 60 minutes at 2.4 ATA once a day for 20 days. $^{41}$ Again in rabbits, $18 \mathrm{HBO}$ sessions with a protocol of 90 minutes at 2.5 ATA once a day were performed together with distraction. This arrangement caused an increase in osteoblastic activity at the distraction osteogenesis site when applied before the operation. ${ }^{42}$ In a study on rats by Okubo et $\mathrm{al}^{43}$ HBO was performed for 60 minutes at 2 ATA, once a day for 3, 7, or 21 days. Based on these investigations, the authors determined to use a protocol of five consecutive HBO sessions in this study. Finally further studies are needed to make use HBOT treatment protocols due to its noticed improvement in periodontal attachments regarding benefits towards reducing the impact of relapse during retention of teeth after orthodontic treatment.

\section{CONCLUSIONS}

It is suggested that hyperbaric oxygen therapy (HBOT) may be useful in reducing unwanted tooth mobility noticed near the conclusion of orthodontic treatment especially in patients who commenced their treatment with moderate to advanced periodontal problems represented by reduced alveolar bone height at variable degrees. 
Egyptian

Orthodontic Journal

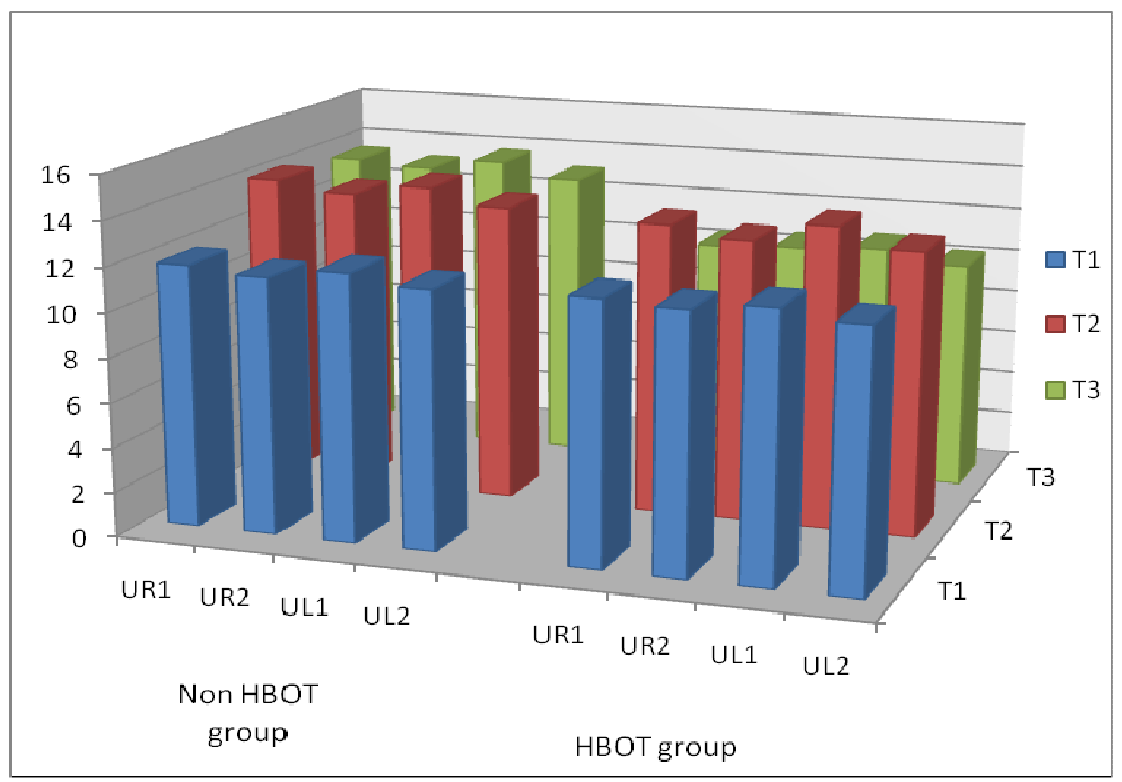

Fig 3: Three-D bar graph showing the mean difference in mobility of upper teeth between the two groups.

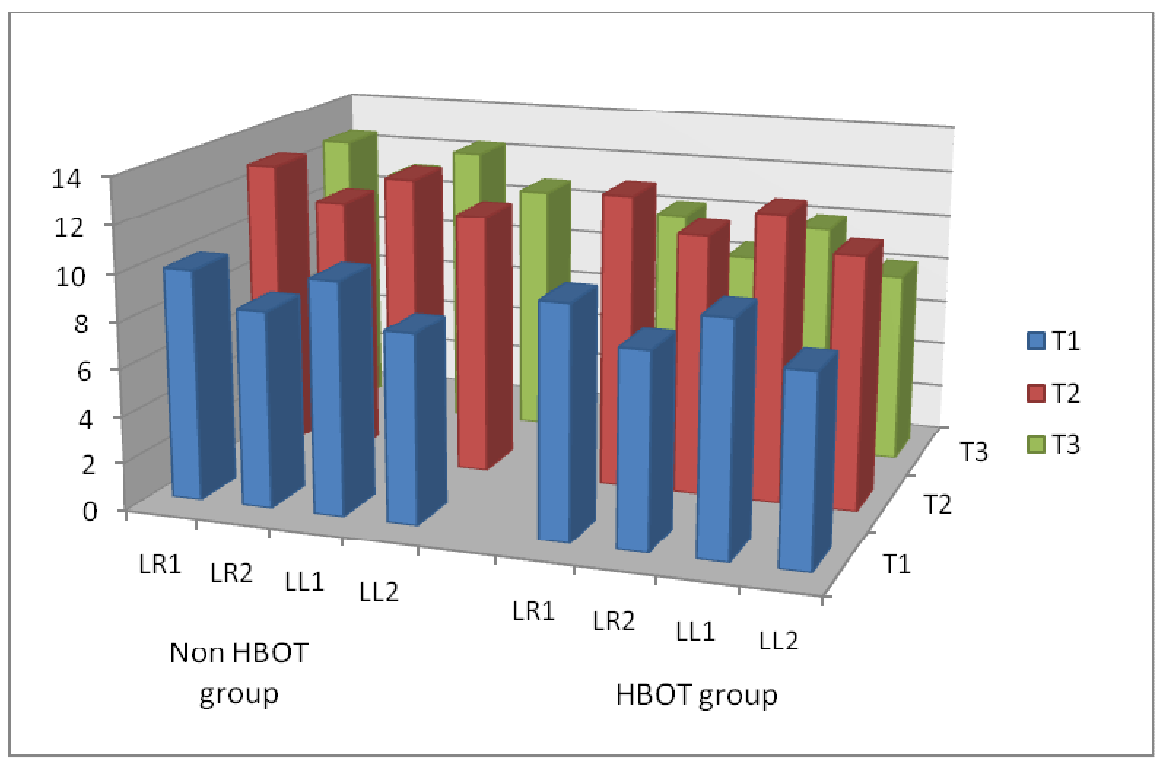

Fig 4: Three-D bar graph showing the mean difference in mobility of lower teeth between the two groups.

Volume 38-December 2010 


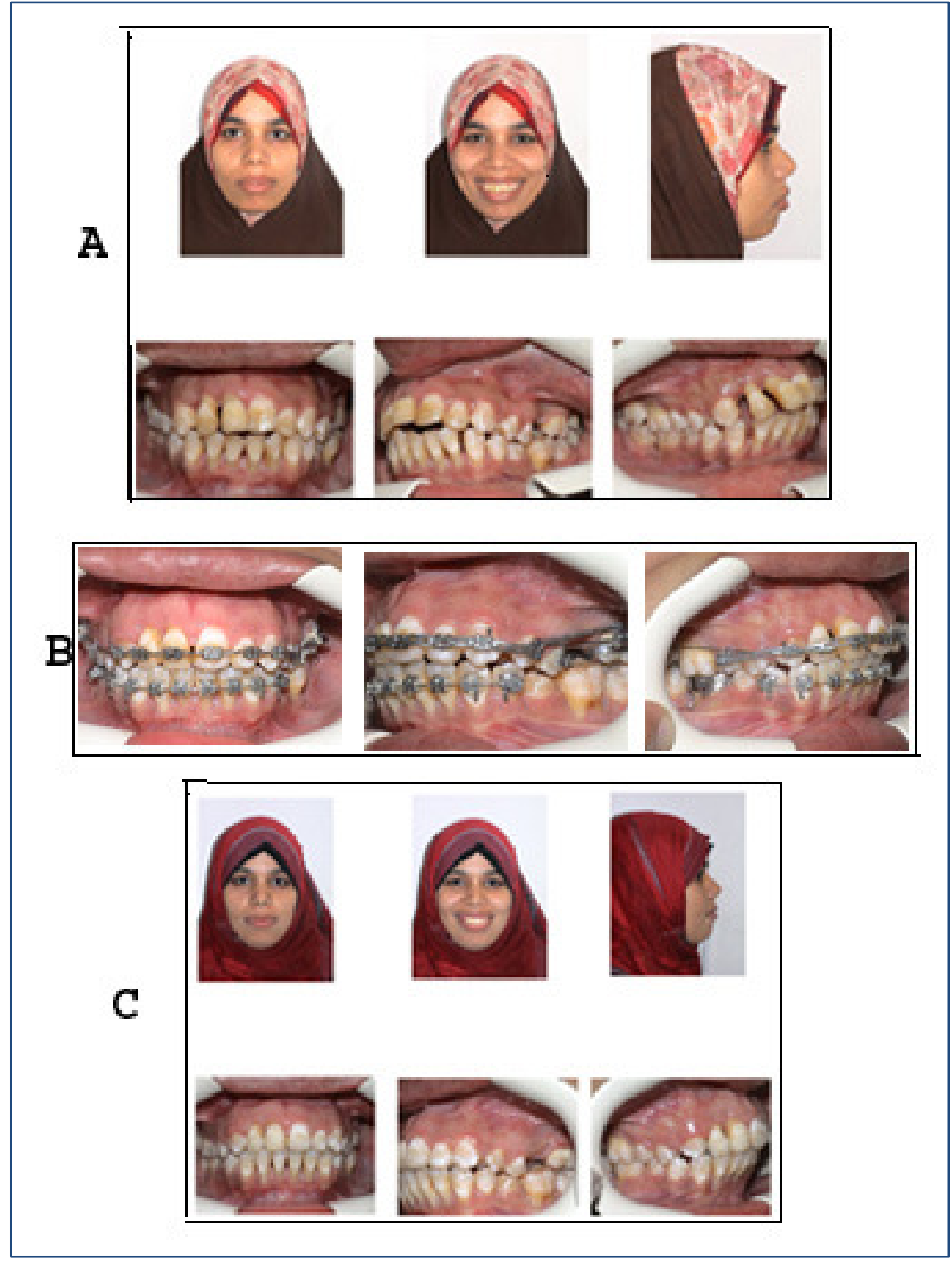

Fig 5: Case 3 in HBOT group, A: pre- treatment, B: orthodontic treatment after HBOT, and $\mathrm{C}$ : post treatment. 


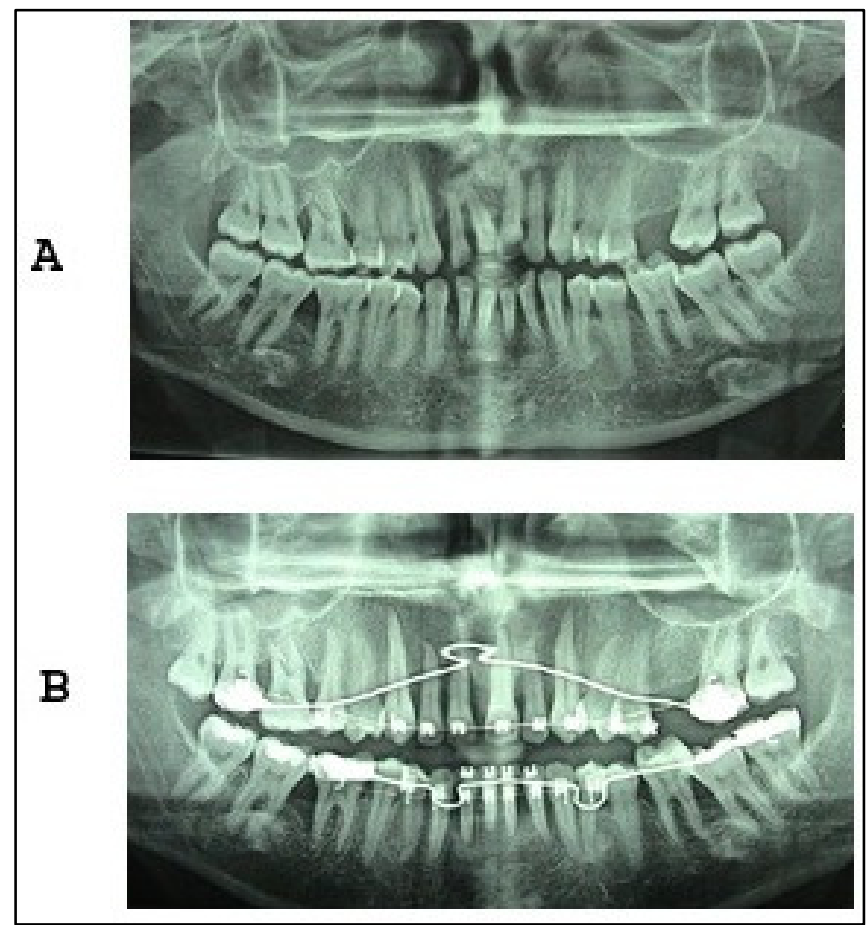

Fig 6: Panoramic x-rays for case $3 \mathrm{~A}$ : pre- treatment and B: during orthodontic treatment after HBOT.

\section{REFERENCES}

1. Reitan, K. Some factors determining the evaluation of forces in orthodontics. American Journal of Orthodontics, 1957, 43, 32-45.

2. Norton, L. A. The effect of aging cellular mechanisms on tooth movement, Dental Clinics of North America, 1988, 32, 437- 446.

3. Reitan, K. and P. Rygh. Biomechanical principles and reactions. In: Graber TH, Vanarsdall RL, eds. Orthodontics, Current Principles and Techniques. 2nd ed. St. Louis, Mo: CV Mosby; 1994:96- 192.

4. Rygh, P. Ultrastructural changes in tension zones of rat molar periodontium incident to orthodontic tooth movement. Am J Orthod 1976. 70:269-281. 
5. Kyomen, S. and K. Tanne. Influences of aging changes in proliferative rate of PDL cells during experimental tooth movement in rats. Angle Orthod 1997. 67:67-72.

6. Tanne, K., Y. Inoue, and M. Sakuda . Biomechanical behavior of the periodontium before and after orthodontic tooth movement. Angle Orthod 1995. 65:123-128.

7. Tanne, K., S. Yoshida, T. Kawata, A. Sasaki, J. Knox , and M. L. Jones . An evaluation of the biomechanical response of the tooth and periodontium to orthodontic forces in adolescent and adult subjects. Br J Orthod 1998. 25:109-115.

8. Sjölien T, Zachrisson BU. Periodontal bone support and tooth length in orthodontically treated and untreated persons. American Journal of Orthodontics 1973;64:28-37.

9. Zachrisson BU, Alnæs L. Periodontal condition in orthodontically treated and untreated individuals. II. Alveolar bone loss: radiographic findings. Angle Orthodontist 1974;44:48-55.

10. Boyd RL, et al,. Periodontal implications of orthodontic treatment in adults with reduced or normal periodontal tissues versus those of adolescents.American Journal of Orthodontics and Dentofacial Orthopedics 1989;96:191-198.

11. Lindhe J, Svanberg G. Influence of trauma from occlusion on progression of experimental periodontitis in the beagle dog. Journal of Clinical Periodontology 1974;1:3-14.

12. Nyman $\mathrm{S}$, et al. The effect of progressive tooth mobility on destructive periodontitis in the dog. Journal of Clinical Periodontology 1978;5:213-225.

13. Ericsson I, Lindhe J. Effect of longstanding jiggling on experimental marginal periodontitis in the beagle dog. Journal of Clinical Periodontology 1982;9:497-503.

14. Melissa L. Edwards, DVM, DACVECC Hyperbaric oxygen therapy. Part 1: history and Principles Journal of Veterinary Emergency and Critical Care 20(3) 2010, pp 284-297. 
15. Getulio R Nogueira-Filho; Bruno T Rosa; Joao R David Neto. Effects of hyperbaric oxygen therapy on the treatment of severe cases of periodontitis. UHM; Mar/Apr 2010; 37, 2; 19: 12,13.

16. lazzeti P, Mantovani M. Hiperoxia Hiperbarica em Infec $\sim$ oes Graves e Sepse-Conceitos e Perspectivas. (Portuguese). Rev Medicina Intensiva 1998;31:412423.

17. Marx R. A New Concept in the Treatment of Osteoradionecrosis. J Oral Maxillofac Surg 1983;41:351-357.

18. Gordillo GM, Sen CK. Revisiting the essential role of oxygen in wound healing. Am J Surg. 2003;186(3):259-263.

19. Gottrup F. Oxygen in wound healing and infection. World J Surg. 2004;28(3):312-315.

20. Tibbles PM, Edelsberg JS. Hyperbaric-oxygen therapy. N Engl J Med. 1996;334(25):1642-1648.

21. Kindwall EP, A history of hyperbaric medicine. In: Kindwall EP, Whelan $\mathrm{H}$, eds. Hyerbaric medicine practice. Flagstaff, AZ: Best Publishing Co. 1999:1-20.

22. MacFarlane C, Cronje FJ. Hyperbaric oxygen and surgery. S Afr J Surg. 2001;39(4):117-121.

23. Tuncay OC, Ho D, Barker MK. Oxygen tension regulates osteoblast function. Am J Orthod Dentofacial Orthop. 1994; 105(5):457-463.

24. Shaw JL, Bassett CA. The effects of varying oxygen concentrations on osteogenesis and embryonic cartilage in vitro. J Bone Joint Surg Am. 1967;49(1):73-80.

25. Nilsson P, Albrektsson T, Granstrom G, Rockert HO. The effect of hyperbaric oxygen treatment on bone regeneration: an experimental study using the bone harvest chamber in the rabbit. Int $\mathrm{J}$ Oral Maxillofac Implants. 1988;3(1):43-48.

26. Gotsko E, Palamarchuk V, Mys'kin O. Experience in using hyperbaric oxygenation in the overall treatment of periodontitis. Stomatologiia 1980;59:23-24. 
27. Sumachev V. Hyperbaric oxygenation in the combined therapy of periodontosis. Stomatologiia 1983;62: 22-24.

28. Shannon M, Hallmon W, Mills M, et al. Periodontal wound healing a responses to varying oxygen concentrations and atmospheric pressures. J Clin Periodontol 1988; 15:222-226.

29. Chen T, Zhou, Y, Liu J, et al. Biological effects of hyperbaric oxygen on human severe periodontitis. Undersea Hyper Med 2002;29: 159-166. 6.

30. Chen T, Lin S, Liu, G, et al. Effects and holding time of hyperbaric oxygen on human severe periodontitis. Shanghay Kou Qianq Yi Xue $2003 ; 12: 403-405$.

31. Signoretto C, Bianchi F, Burlacchini G, Canepari P.Microbiological evaluation of the effects of hyperbaric oxygen on periodontal disease. New Microbio12007;30:431-437.

32. Tanner A, Haffer C, Bratthal G, et al. A study of bacterial associated with advanced periodontitis in man. J Clin PeriodontoI1979;6: 278-307.

33. Dzink J, Haffajee A, Tanner A, et at. Gram negative species associated with active destructive periodontal lesions. J Clin Periodontol 1985; 12:639647.

34. Dzink J, Socransky S, Haffajee A. The predominant cultivable microbiota of active and inactive lesions of destructive periodontal disease. J Clin periodontol 1988;15:316-323.

35. Eiji Tanaka et al. Longitudinal Measurements of Tooth Mobility during Orthodontic Treatment Using a Periotest. The Angle Orthodontist 2005; 75: 101-105.

36. Kaneko, T. M. Relationship between the stiffness of the dental implant-bone system and the duration of the implant-tapping rod contact. Med Eng Phys 1994. 16:310-315.

37. Andresen, M., I. Mackie, and H. Worthington. The Periotest in traumatology. Part I. Does it have the properties necessary for use as a clinical device and can the measurements be interpreted? Endod Dent Traumatol 2003. 19:214-217. 
Egyptian

Orthodontic Journal

38. Linge, L. and B. O. Linge . Patient characteristics and treatment variables associated with apical root resorption during orthodontic treatment. Am J Orthod Dentofacial Orthop 1991. 99:35-43.

39. Blake, M. , D. G. Woodside, and M. J. Pharoah . A radiographic comparison of apical root resorption after orthodontic treatment with the edgewise and Speed appliances. Am J Orthod Dentofacial Orthop 1995. 108:76-84.

40. Sawai T, Niimi A, Takahashi H, Ueda M. Histologic study of the effect of hyperbaric oxygen therapy on autogenous free bone grafts. $\mathrm{J}$ Oral Maxillofac Surg. 1996;54(8):975-981.

41. Sawai T, Niimi A, Johansson CB, Sennerby L, Ozeki K, Takahashi H, Albrektsson T, Ueda M. The effect of hyperbaric oxygen treatment on bone tissue reactions to c.p. titanium implants placed in free autogenous bone grafts. A histomorphometric study in the rabbit mandible. Clin Oral Implants Res. 1998;9(6):384-397.

42. Muhonen A, Peltomaki T, Knuuti J, Raitakari O, Happonen RP. Osteoblastic activity of the rabbit temporomandibular joint during distraction osteogenesis assessed by [18F] fluoride positron emission tomography. Eur J Oral Sci. 2002; 110(2):144-148.

43. Okubo Y, Bessho K, Fujimura K, Kusumoto K, Ogawa Y, Iizuka T. Effect of hyperbaric oxygenation on bone induced by recombinant human bone morphogenetic protein-2. Br J Oral Maxillofac Surg. 2001;39(2):91-95. 